\title{
Parental training and externalizing behaviors of children with severe hearing loss
}

\author{
Guita Movallali ${ }^{1}$, Mohsen Amiri ${ }^{2 *}$, Abas Nesayan ${ }^{3}$, Roghaye Assady Gandomani ${ }^{3}$ \\ Received: 16 Nov 2016 \\ Published: 19 Dec 2017
}

\begin{abstract}
Background: Externalizing behavior in deaf children causes many psychological problems for their parents. Aggression and rule breaking behaviors in children with severe hearing loss may cause psychological problems in parents and in managing children's behavior. Consequently, the present study aimed at investigating the effect of parental behavioral training of mothers on reducing the externalized behaviors (aggression and rule breaking behavior) of their 9- to 10- year old children with severe hearing loss.

Methods: This was an experimental study with pretest, posttest, and a control group. The research population included all students with severe hearing loss and their mothers. Thus, 30 mothers whose children had the most severe hearing loss were selected as our main sample among 80 mothers who had completed the Child Behavior Checklist. Then, they were placed into the experimental $(\mathrm{n}=15)$ and control groups $(\mathrm{n}=15)$ after being matched based on age, educational level, and socioeconomic status. The research tool was Child Behavior Checklist-Persian Version. The parental behavior training was provided for the experimental group in nine 90 minute sessions.

Results: The results of the present study indicated the effectiveness of experimental treatment on decreasing the aggressive behaviors of children of mothers in the experimental group compared to mothers of the control group ( $\mathrm{p}=0.001)$. Moreover, the results revealed a decrease in rule breaking behaviors $(p=0.007)$ in children of mothers of the experimental group compared to mothers of the control group.

Conclusion: Parents' behavioral training is important in decreasing the aggressive and offensive behaviors in children with severe hearing loss who are at risk of behavioral problems. Furthermore, some research has highlighted the necessity of such trainings for parents of these children. Thus, the present study, emphasizing the importance of childhood problems, found that mothers' behavioral training could prevent behavioral problems of school-aged children with hearing loss and reduce the recurrence of such problems.
\end{abstract}

Keywords: Children with severe hearing loss, Parent behavioral training, Aggression, Rule breaking behaviors

Copyright $@$ Iran University of Medical Sciences

Cite this article as: Movallali G, Amiri M, Nesayan A, Assady Gandomani R. Parental training and externalizing behaviors of children with severe hearing loss. Med J Islam Repub Iran. 2017 (19 Dec);31:111. https://doi.org/10.14196/mjiri.31.111

\section{Introduction}

Hearing loss is the most common sensory-neural defect in humans; and among 1000 children, 1 is born with a stable severe to profound sensory-neural hearing loss (1). However, recent studies found this number to be 1 in 650 children (2). Parents of such children have to deal with fundamental issues in caring for the children (3). These sensory disabilities are sometimes associated with behav-

Corresponding author: Dr Mohsen Amiri, m.amiri@znu.ac.ir

1. Pediatric Neurorehabilitation Research Center, University of Social Welfare and Rehabilitation Sciences, Tehran, Iran.

2. Department of Psychology, University of Zanjan, Zanjan, Iran.

3. Department of Psychology, University of Bojnord, Bojnord, Iran. ioral-emotional problems, which can be called externalized behavioral problems (4).

The crucial characteristics of children with hearing impairment appear in behavioral, emotional, and academic issues in which cases influence the interaction of the parents with their children (5). Topol, Girard, Pierre, Tucker, and Vohr (3) suggest that the prevalence of behavioral

$\uparrow$ What is "already known" in this topic:

One of the most common treatment for behavioral problems of children is the behavioral training of parents which has been used less in the case of deaf children with behavioral problems.

$\rightarrow$ What this article adds:

Results from this study showed that techniques of behavioral training of parents can help to decrease the behavioral problems such as aggression and rule breaking behaviors in children with severe hearing loss by influencing parenting style. 
problems such as aggressive behaviors in deaf children is high. On the other hand, there is clear evidence that such behavioral problems have devastating effects on parents' child-rearing practices as well as their psychological wellbeing.

The prevalence of emotional and behavioral problems among deaf individuals has reported to be more than $40 \%$ (6). These children have more behaviorial problems compared to their normal hearing peers; some studies suggest that $15 \%$ to $20 \%$ of children with severe hearing loss have serious clinical behaviorial problems (7).

On the other hand, one of the most important behavioral problems associated with the classification of externalizing behaviors are aggressive and rule breaking behaviors, which are the most common reasons with which children and adolescents with hearing loss referr to mental health clinics (8). Many studies have emphasized that aggression and behavioral problems in children can lead to future antisocial and rule breaking behaviors (9). In fact, children with hearing loss and aggressive behaviors show less proper behaviors when communicating with their peers. On the other hand, this feature prevents the child's relationship with peers and will disable the child in learning (10). There is a wide range of factors causing behavioral problems in deaf children, some of which are associated with their parents' parenting styles (11). Children with severe hearing loss are usually less compliant, more negative, and less able to follow parental instructions and cannot adhere to family rules compared to other children of their age. Their parents may use maladaptive behaviors to control their children's behavior such as applying excessive control strategies, which contributes to the aggravation of these children's condition, leading to consequences such as serious parent-child conflicts and exacerbation of the aggression symptoms in children (4).

Previous studies have shown that the relationship between hearing mothers and their children with hearing loss is more rigid, intervening, and negative compared with the communication of hearing mothers and hearing children. This relationship will cause hearing impaired children to be less responsive and active (12). The parents of children with hearing loss are more likely to use physical punishments (13).

Thus, identification and therapeutic interventions for children who are at risk of behavioral problems are necessary (14) because parents of these children are faced with the pressures of trying to manage their child's activities and daily tasks (15). Therefore, most of these parents deploy some types of methods which exacerbate their children's condition, and by imposing strict controls on children, they create a situation which result in serious conflicts with their children and more severe behavioral problems $(16,17)$. Parents of deaf children are more vulnerable to experience conflicts with their children and may use inappropriate parenting styles (4). Research findings imply that one of the reasons for behavioral problems, such as aggression, in children is child abuse. Deaf children are more vulnerable to physical abuse and are more prone to strict control by their parents compared to other children $(18,19)$.
One of the training methods for the treatment and prevention of aggression and rule breaking behaviors is behavioral parent training (20). It is based on the principles of social learning that helps parents to recognize the circumstances and consequences of inappropriate behavior of their children, target them, monitor their children's behaviors, use deliberate and planned ignorance, temporary banning and other nonphysical techniques without corporal punishment, and modify the behavior of their children, and reinforce appropriate behavior by attention, verbal encouragement and rewards to achieve desirable behaviors $(21,22)$.

For example, in this study, parents of children newly diagnosed with developmental disorders were enrolled in a training program for parents for 20 weeks and were trained for behavior management interventions (23). The mental health indicators (such as insomnia, anxiety, somatic problems and system malfunctions of their families) of parents participating in the research program improved compared to those parents who had just benefited from the advisory services. One of the goals of this intervention program was to reduce parental stress and increase parenting competence in families with children suffering from developmental disorders. The results revealed that providing early intervention to parents with deaf children reduced parental stressors and increased feeling of competence in parenting. With respect to the role of behavioral parent training in reducing rule breaking behaviors and aggression, it seems that training and applying behavior modification methods can help reduce externalized behaviors in children with hearing loss. Hence, this study aimed at answering the following question: Is behavioral parent training of mothers effective in decreasing the rule breaking behaviors and aggression of children with severe hearing loss?

\section{Methods}

\section{Participants and Procedures}

This research was conducted experimentally through pretest, posttest, and a control group. The population of this study included all the primary school students with severe hearing loss in the academic year of 2015 and their mothers (All the mothers of children who referred to the exceptional children school and to the social welfare therapeutic center in Anza, a city in West of Iran were included.). Thirty mothers (15 mothers in the experimental group and 15 in the control group) whose children had severe hearing loss and the highest scores in aggression subscale were selected as our main sample among the 60 mothers who had completed the Child Behavior Checklist-Persian Version(24). The sampling method was convenience and the participants were matched and assigned randomly into experimental and control groups. In quantitative researches, the use of the biggest sample is considered a rule. However, in many studies, time and budget limitations limit the number of individuals in a sample. Thus, the researchers have proposed a rule to determine the minimum sample size required for different methods of research. In experimental studies, 15 individuals were suggested for each group; however, this number may 
Table 1. Summary of operating instruction sessions of parent behavioral training

First session: This session essential information about the nature, prevalence, course, prognosis, etiology and treatment of behavioral problems in children of deaf parents was presented.

Second session: In this session necessary background to explain the principles of formation of the importance of behavior and behavior management was provided, and general principles of behavior management such as positive reinforcement, reinforcement was described separately.

Third session: In this session it was emphasized on the role and importance of parents on child behavior and according to the principles of positive behavior and ignoring inappropriate behaviors were taught.

Fourth Session: In this session, positive attention to parents' command obedience and adherence to the regulations of families was discussed.

Fifth Session: The token economy was taught.

Sixth Session: The use of fines and deprivation methods were taught.

Seventh session: Behavior Management in public position was taught.

Eighth session: Improve the child's behavior at school by house was raised and by teaching recording children's positive behaviors at home and ways to rate these behaviors conduct and then the sessions were finished.

Ninth session: In this session a quick tour of the lessons learned from the entire program was done, and then it was discussed how to deal with problems in the future.

change depending on the availability of the participants (25). In the present study, 15 participants were selected for each of the experimental and control groups. The controls were matched with respect to demographic characteristics. Level of parental education was used as an indicator of socioeconomic status. The mean age for children in the experimental group was $9.65(\mathrm{SD}=1.6)$, whereas the mean age for children in the control group was 9.45 $(\mathrm{SD}=1.2)$. The mean age of the parents in the experimental group was 35.5 years $(\mathrm{SD}=3.4)$, whereas the mean age for parents in the control group was 35.2 years $(\mathrm{SD}=3.3)$. The mean educational years for mothers in the experimental group was $12(\mathrm{SD}=1.2)$, whereas the mean educational years for mothers in the control group was 11 $(\mathrm{SD}=1)$. Income level for each family varied between 15 000000 Rials to 20000000 Rials per month (The experimental group parental income was $\mathrm{M}=16500$ 000, and that of the control group was $M=17500000$.).

The inclusion criteria for the participants of this study were as follow: The type of hearing loss was one of the inclusion criteria. In this study, all children with hearing loss were mainly affected by severe hearing loss. The age of the mothers was another inclusion criterion. All the mothers were between 37 to 39 years. Single parent or 2 parent families were also considered, but in this study, all were 2 parent families. The number of children with severe hearing loss was considered, and all the households had a child with severe hearing loss. Children's age was another inclusion criterion. Mothers' education was also considered; all the mothers were college-educated in our sample. Not participating in more than 2 behavioral training sessions was the exclusion criterion. Then, training was provided for the experimental group. The variables of aggression and rule breaking behaviors were again measured after the training was completed. Because the number of questions in the aggression subscale was not much, the instructor clarified each question using different examples.

The program content had been adopted from Barkley's Parent Education Program (1997) (25). Methods and techniques used in this research were supposed to provide trainings. They included lectures, discussions, and participation of the members of the group, an educational booklet, and a CD or a tape session summary. This training was done by a licensed psychologist with a doctoral degree and professional practice in the field of psychology.
There were nine weekly sessions and 1 booster session. Each session lasted approximately for 90 minutes. For each session, parents were asked to complete a specific homework. At the beginning of each session, leaders reviewed the homework from the last session before turning in the homework to case managers. Whenever parents made mistakes or had problems in their homework, the case managers would meet with the parents immediately after the training session to discuss the problems. A summary of functional instructions of the emotion regulation training is presented in Table 1.

\section{Research Tools}

The following instruments were used in this study:

\section{Children's Externalizing Behaviors}

The Child Behavior Checklist (CBCL; Achenbach, 1991)(26): It is a widely used measure of children's social/academic functioning and behavior problems. A composite score for externalizing behavior problems is based on parental responses to 118 behavior problem items. In the present study, both parents completed this measure, yielding 2 scores for child externalizing behaviors, 1 based on mothers' reports, and 1 based on fathers' reports. Good short-term test-retest reliability ( 93 for total problems) has been reported for this measure (26), and high internal consistency reliability was observed for mothers in the present study (Cronbach coefficient 0/86). The widespread use of the CBCL facilitates comparison of the present findings with those of prior studies. In this study, the Iranian version of the Child Behavior Checklist Questionnaire was used (24). This questionnaire gathers normative data on a sample of 203 Iranian children and adolescents. In that study, the sensitivity, specificity, and OMR were calculated for these cutoff points with reference to DSM-IV. Based on the total scores obtained from our samples, the score of 35 had the best sensitivity $(79.1 \%)$, the best specificity $(98.5 \%)$, and the least OMR $(5.4 \%)(24)$.

\section{Ethical Considerations}

In this research, moral considerations were considered and participants were asked to fill a consent form. Moreover, they were presented with the necessary information about the method and objective of the research. Advantages and the nature of the research and its duration 
were also explained to the participants. If the participants had any questions, they were provided with answers.

\section{Statistical Analysis}

Levine's test was used to check the homogeneity of the variances of the data. Subsequently, data were analyzed using SPSS-16 statistical software by analysis of covariance. ANCOVA was used as one of the statistical control methods in the studies including pretest and posttest because it can control the effect of confounding factors of the pretest. In such studies, pretests may affect the results of the posttest because participants may become familiarized with scales and questionnaires. $P=0.05$ was considered as statistically significant.

\section{Results}

The descriptive results of the study in both the pretest and the posttest are presented for each group in Table 2.

Based on Table 2, the mean $\pm \mathrm{SD}$ of the pretest score for aggressive behaviors of the experiment group was $16.66 \pm 3.22$, and that of the posttest was $13.80 \pm 2.85$. Moreover, the mean \pm SD of the pretest rule breaking behaviors score of the experimental group was $14.33 \pm 2.66$ and it was 11 for that of the posttest.

We used tests of homogeneity of regression slopes between random variables (pretest) and dependent variables and Leven test before using analysis of covariance. In this study, the slopes of the regression line in all variables (aggressive behaviors $(\mathrm{F}=0.411, \mathrm{P}=0.321)$, and rule breaking behaviors $(\mathrm{F}=0.384, \mathrm{P}=0.287)$ ) were parallel. Homogeneity of variances was one of the other assumptions of this analysis. Levene's test was used to check the homogeneity of the variances of the 2 groups in pretest and posttest.

Levene test was used for any of the variables that were not statistically significant (posttests), aggressive behaviors $(\mathrm{F}=0.125, \mathrm{P}=0.583)$, and rule breaking behaviors $(\mathrm{F}=0.168, \mathrm{P}=0.562)$. Thus, the assumption of homogeneity of the variances was approved. Therefore, considering the establishment of the main assumptions of this test, we are allowed to use it.

According to Table 3, there were significant differences between the average scores of aggressive behaviors ( $\mathrm{F}$ (1, $27)=15.39 \& \mathrm{P}=0.001)$ and rule breaking behaviors $(\mathrm{F}$ $(1,27)=8.64 \& \mathrm{P}<0.05)$ between the experimental and the control groups $(\mathrm{P}=0.05)$. Therefore, it can be concluded that at the posttest, behavioral parent training will decrease externalizing behaviors (aggression and rule breaking behaviors) among children with severe hearing loss compared to the control group. Thus, behavioral parent training induced change in groups.

\section{Discussion}

This study aimed at seeking an answer to the following question: Is providing behavioral parent training to mothers effective in reducing rule breaking behaviors and aggression in children with severe hearing loss? The results of the present study revealed that presenting behavioral trainings to mothers significantly improved externalizing behaviors of their children with severe hearing loss. Many other researchers had emphasized the efficacy of training of mothers in behavior parenting strategies to decrease their children's behavioral aggression. The results of this study revealed that providing behavioral parent trainings for mothers significantly decreased the effect on aggressive behavior problems in such children $(27,28)$. This result is in line with previous findings $(21,28)$ in the effectiveness of behavioral parent training in decreasing aggression and oppositional behavior in children with behavioral problems and exceptional children.

The following points can be considered as the reasons of the efficacy of such trainings for decreasing behavioral aggression among children. A considerable part of the problems of children with hearing loss and behavioral problems appear and continue in relation to parents, particularly mothers. Therefore, teaching correct behavioral methods to mothers of such children and training them to use appropriate regular reinforcing and punitive approaches will increase the probability of less aggressive behaviors in children.

Furthermore, most mothers of children with behavioral problems utilize negative harsh styles to control their children. Because attention skills are of great importance in forming children's behaviors, this section of behavior training also includes modifying the methods through which mothers pay attention to their children. Important attention skills, such as listening and paying positive attention, may help parents during therapy to learn how to pay attention to their children without interrupting them and asking them questions and to form children desirable behavior by making positive statements (22).

Another result of this study was that the trained mothers reported decreased rule breaking behaviors among their children with severe hearing loss. This is consistent with the findings of many other researchers $(29,30)$. The focus of these trainings is on the interaction between mothers and their children, assuming that the child's mood and mother's behavior is interactive. For instance, when the

Table 2. Descriptive statistics of aggression and rule breaking behaviors among children with severe hearing loss

\begin{tabular}{|c|c|c|c|c|c|c|c|c|}
\hline \multirow[t]{3}{*}{ Dependent variables } & \multicolumn{4}{|c|}{ Experimental } & \multicolumn{4}{|c|}{ Control } \\
\hline & \multicolumn{2}{|c|}{ Pre-test } & \multicolumn{2}{|c|}{ Post-test } & \multicolumn{2}{|c|}{ Pre-test } & \multicolumn{2}{|c|}{ Post-test } \\
\hline & Mean & SD & Mean & SD & Mean & SD & Mean & SD \\
\hline Aggression & 16.66 & 3.22 & 13.80 & 2.85 & 16.73 & 4.19 & 17.00 & 2.29 \\
\hline Rule Breaking & 14.33 & 2.66 & 11.00 & 3.16 & 14.40 & 2.88 & 14.15 & 3.25 \\
\hline
\end{tabular}

Table 3. Results of Analysis of Covariance of Aggression and Rule Breaking Behaviors in the Experimental and Control Groups

\begin{tabular}{lccc}
\hline Dependent Variables & Mean Square & F & Pvalue \\
\hline Aggression & 103.79 & 15.39 & 0.001 \\
Rule breaking & 59.97 & 8.64 & 0.007 \\
\hline
\end{tabular}


mother feels her attempts to control the child's aggressive behavior does not work, she may think her efforts are ineffective and her child will never change. Parent-child dyadic relationship may be influenced by such feelings. Moreover, it may make the mother to stop her attempts to change the child's misbehaviors. Furthermore, before didactic sessions, mothers' punitive measures were inefficient, inconsistent, often irrelevant to the child's misbehavior, and mothers most likely chose physical punishment and punishments not suitable to the child's developmental stage to bring his/her misbehaviors under control. In group sessions, mothers were warned about the adverse consequences of physical punishment and its long-lasting negative outcomes in the child's future life and were taught correct ways of punishment as well as how to use it to shape behaviors (22). Methodological limitations of this study (sampling and the instruments used) hinder the generalization of the results to other methods and instruments. Time restriction for providing education and lack of follow-up were among the other limitations of this study.

\section{Conclusion}

According to our results, behavioral parent training can have decreasing effects on rule breaking and aggressive behaviors in children with severe hearing loss. According to the results and considering the limitations mentioned in this research, it is suggested that other individuals who are in contact with children closely such as parents, teachers, and other family members can better identify the problems of these children and contribute to further improvement of these children.

\section{Acknowledgement}

This article was extracted from the research proposal approved by University of Social Welfare and Rehabilitation Sciences. The deputy of research \& technology of University of Social Welfare and Rehabilitation Sciences financially supported this study.

\section{Conflict of Interests}

The authors declare that they have no competing interests.

\section{References}

1. Prasad S, Cucci RA, Green GE, Smith RJH. Genetic testing for hereditary hearing loss: Connexin 26 (GJB2) allele variants and two novel deafnesscausing mutations (R32C and 645-648delTAGA). Human Mutation. 2000;16:502-508.

2. Snoeckx RL, Huygen PLM, Feldmann D, Marlin S, Denoyelle F, Waligora J. GJB2 mutations and degree of hearing loss: a multicenter study. Am J Hum Genet. 2005;77:954-957.

3. Topol D, Girard N, Pierre L, Tucker R, Vohr B. The effects of maternal stress and child language ability on behavioral outcomes of children with congenital hearing loss at 18-24 months. Early Human Development. 2011;87:807-811.

4. Quittner AL, Barker DH, Cruz I, Snell C, Grimley ME, Botteri M. CDaCI Investigative Team. Parenting Stress Among Parents of Deaf and Hearing Children: Associations with Language Delays and Behavior Problems. Parenting: Science and Practice. 2010;10(2):136155.

5. Quittner A, Glueckauf R, Jackson D. Chronic parenting stress: Moderating versus mediating effects of social support. Journal of Person- ality and Social Psychology. 1990;59:1266-1278

6. Hindley PA, Hill PD, McGuigan S, Kitson N. Psychiatric disorder in deaf and hearing impaired children and young people: A prevalence study. Journal of Child Psychology and Psychiatry. 1994;35:917-934.

7. Hindley PA. Mental health problems in deaf children. Current Paediatrics. 2005; 15:114-119.

8. Webster-Stratton C, Reid J, Hammond M. Preventing Conduct Problems, Promoting Social Competence: A Parent and Teacher Training Partnership in Head Start. Journal of Clinical Child Psychology. 2001;30(3):283-302.

9. Stewart A, Dennison S, Waterson E. Pathways form child Maltreatment to javemile offendibg. School of criminology and criminal justices, Grtifft University. 2002.

10. Cavell TA, Elledage LC. Working With Parents of Aggressive Children: A Practitioner's Guide. Washington, D.C.: American Psychological Association. 2000.

11. Knutson JF, Johnson CR, Sullivan PM. Disciplinary choices of mothers of deaf children and mothers of normally hearing children. Child Abuse Negl. 2004;28:925-37.

12. Pipp-Siegel S, Biringen Z. Assessing the quality of relationships between parents and children: the emotional availability scales. Volta Rev. 1998; 7:237-249.

13. Knutson JC, Sullivan PM. Disciplinary choices of mothers of deaf children and mothers of normally hearing children. Child Abuse Neglect. 2004;28:925-937.

14. Danforth JS, Harvey E, Ulaszek WR, Mckee TE. The outcome of group parent training for families of children with attention deficit hyper activity disorder and defiant aggression behavior. Journal of Behavior Therapy and Experimental Psychiatry. 2006;37:188-205.

15. Huang H, Chao C, Tu CC, Yang PC. Behavioral parent training for Taiwanese parent of children with attention-deficit hyperactivity disorder. Psychiatry \& Cilinical Neurosciences. 2003;57:275-281.

16. Essau C. Child and adolescent psychopathology. 2006, London: Brunner-Routledge.

17. Fabiano GA, Pelham Jr WE, Coles EK, Gnagy EM, ChronisTuscano A, O'Connor BC. A meta-analysis of behavior treatment for attention-deficit /hyperactivity disorder. Cilinical Psychology Review. 2008;52:1-12.

18. Barnett SJ, Klein JD, Pollard RQ. Community participatory research to identity health inequities with deaf sign language users. Am Journal Public Health. 2011;101(12):2235-2238.

19. Fellinger J, Holzinger D, Sattel H, Laucht M. The impact of language skills on mental health in teenagers with hearing impairments. Acta Psychiatrica Scandinavica. 2009;120(2):153-159.

20. Greenhill L, Osman B. Ritalin: Theory \& practice 2000; USA: Mary Ann Libert.

21. Chronis AH, Chacho A, Fabiano GA, Pelham W. E Enhancement to the Behavioral Parent Training Paradigm for Families of children with ADHD: Review and future direction. Clinical Child and Family Psychology Review. 2004;7(2):1-27.

22. Amiri M, Behpajooh A. The effect of behavioral parent training on mothers of children with attention deficit hyperactivity disorder International Journal Behavioral Science. 2016;10(1):6-12.

23. Tonge B, Brereton A, Kiomal M, Mackinnon A, King N, Rinehart N. Effects on parental mental health of an education and skills training program for parents of young children with autism: A randomised control trial. Journal of the American Academy of Child and Adolescent Psychiatry. 2006;45:561-569.

24. Shahrivar Z. Validity of the Child Behavior Checklist-Persian Version in a Community Sample of Iranian Youths. Iranian Journal of Psychiatry and Behavioral Sciences. 2011;5(1):45-49.

25. Barkley R. Defiant Children: A Clinician's Manual for Assessment and Parent Training, ed. n. edn 1997; New York: Guilford.

26. Achenbach T. Integrative guide for the $1991 \mathrm{CBCL} / 4-18$, YSR and TRF profiles U.o.V. Department of Psychiatry, Editor 1991; Burlington: Vermont.

27. Webster-Stratton CJ. Reid M, Hammond, A. Preventing Conduct Problems, Promoting Social Competence: A Parent and Teacher Training Partnership in Head Start. Journal of Clinical Child Psychology. 2001;30(3):283-302.

28. Mccart M, Priester P. Differential effectiveness of behavioral parent training ad cognitive behavior, behavior therapy For Antisocial youth Journal of Abnormal child psychology. 2006;34(4):525-537.

29. Gimpel G, Holland M. Emotional and Behavioral Problems of Young Children: Effective Interventions in the Preschool and Kin- 
Parental training and children with severe hearing loss

dergarten Years. New York: Guilford press 2002.

30. Hollenstein T. Rigidity in parent - child interaction and the developmental of externalizing and internalizing early childhood. Journal of Abnormal child Psychology. 2004;32(4):595-607. 